\title{
Reverse Revenue Sharing Contract versus Two-Part Tariff Contract under a Closed-Loop Supply Chain System
}

\author{
Zunya Shi, ${ }^{1,2}$ Nengmin Wang, ${ }^{1,2}$ Tao Jia, ${ }^{1,2}$ and Haoxun Chen ${ }^{3}$ \\ ${ }^{1}$ School of Management, Xian Jiaotong University, No. 28 Xianning Road, Xian, Shaanxi 710049, China \\ ${ }^{2}$ The Key Lab of the Ministry of Education for Process Control \& Efficiency Engineering, No. 28 Xianning Road, \\ Xian, Shaanxi 710049, China \\ ${ }^{3}$ Industrial Systems Optimization Laboratory, Charles Delaunay Institute and UMR CNRS 6281, University of Technology of Troyes, \\ 12 rue Marie Curie, CS 42060, 10004 Troyes, France \\ Correspondence should be addressed to Nengmin Wang; nengmin.wang@163.com
}

Received 11 January 2016; Accepted 6 April 2016

Academic Editor: Rosa G. González-Ramírez

Copyright (C) 2016 Zunya Shi et al. This is an open access article distributed under the Creative Commons Attribution License, which permits unrestricted use, distribution, and reproduction in any medium, provided the original work is properly cited.

\begin{abstract}
The importance of remanufacturing has been recognized in research and practice. The integrated system, combining the forward and reverse activities of supply chains, is called closed-loop supply chain (CLSC) system. By coordination in the CLSC system, players will get economic improvement. This paper studies different coordination performances of two types of contracts, twopart tariff (TTC) and reverse revenue sharing contract (RRSC), in a closed-loop system. Through mathematical analysis based on Stackelberg Game Theory, we find that it is easy for manufacturer to improve more profits and retailer's collection effects by adjusting the ratio of transfer collection price through RRSC, and we also give the function to calculate the best ratio of transfer collection price, which may be a valuable reference for the decision maker in practice. Besides, our results also suggest that although the profits of the coordinated CLSC system are always higher than the contradictory scenario, the RRSC is more favorable to the manufacturer than to the retailer, as results show that the manufacturer will share more profits from the system through RRSC. Therefore, RRSC has attracted the manufacturers more to closing the supply chain for economic consideration.
\end{abstract}

\section{Introduction}

In recent years, developed countries have attached importance to the collection of used resources and products. Europe is the progenitor in the field of product collection. From the perspective of management, European Commission enacted relative legislation (e.g., Council Directive 75/442/EEC of 12 July 1975 on waste, which is the first directive of Western Europe aiming at addressing waste management) to promote the product collection activities. Germany also enacted ElektroG Act, which came into force in 2005, to address the recycling problem of WEEE (waste electric and electronic equipment) [1]. From the perspective of business, there are many companies that are known for their return policies, such as the 365-day return policy of Zappo.com and the buyer protection program of Hyundai Motor.
In China, a developing country, the problem of product waste is serious. E-product sales in China have increased sharply during the last 10 years, and China is already the second largest generator of e-waste in the world, with 2.3 million tons generated domestically each year [2]. In addition, according to the survey from the China Household Electrical Appliances Association, the annual amount of the e-products that are out of service has exceeded 0.15 billion. More than 80 percent of disposed electrical equipment is transported to Asia from all over the world, and 90 percent of this equipment is received by China, the largest junkyard of the world. Unless effective actions are taken to solve the problem of waste, the large amount of waste in China will cause the serious consequences in terms of the environment and society. However, although there have been some policies and legislations in China in favor of facilitating product 
return because of the economic and environmental effects, the problem of recycling used products has not been resolved. Therefore, it is important to address this situation in China.

Product return has become a significant and imperative process during the manufacturing operation, which benefits both society and the manufacturer. For some particular industrials, for example, batteries, used product collection will help to diminish the pollution, which is the reason why some governments, such as the EU and the USA, issue legislation to require the enterprises to collect used products. The reverse activities in the supply chain provide manufacturers with enormous economic potential [3]. Efficient and tenable remanufacturing processes may lead to lower manufacturing cost.

Among various strategies for promoting product return, CLSC (closed-loop supply chain) deserves more attention. Over the past decades, there have been a great number of researchers made on this topic and defined it from different angles. Krikke et al. [4] thought that CLSC is a unique system, containing forward and reverse activities, and it will improve the performance in terms of economics and environment. Guide Jr. and Van Wassenhove [3] defined the CLSC as a system, which combines design, control, and operation activities to maximize value creation over the entire life cycle of a product with dynamic recovery of value from different types and volumes of returns. $\mathrm{Zu}$ Jun et al. [5] pointed out that the CLSCs mainly focus on bringing back used products from customers and adding the value of entire products (or its modules, components, parts, and so on) by recovering and remanufacturing. Aydin et al. [6] suggested that CLSC involves a collection of used products from customers and supports various product recovery strategies, such as remanufacturing, recycling and reuse, and managing the relationship and coordinating with supply chain partners, such as manufacturers, suppliers, retailers, and/or remanufacturers. In this paper, we consider the CLSC as an integrated system, combining the forward and reverse activities of supply chains. By designing, operating, and controlling CLSC, the system will get economic improvement. Although different researchers gave different definitions, there is an agreement among them that the CLSC will be sure to improve the economic performance of the system a lot through coordination. Chen and Chang [7] suggested that sometimes members in CLSCs will cooperate with others to form an alliance to improve supply chain efficiency, and this kind of alliance will lead to great benefits and competitive advantages. De Giovanni et al. [8] thought that the decision makers are more likely to close the supply chain because manufacturers can save cost by producing with used materials or parts returned from consumers, which are much cheaper than new ones. Guide Jr. and Van Wassenhove [9] argued that CLSC can add considerable value to the firm. The increased profitability is a strong incentive for enterprises to take responsibility for product return. Therefore, it is necessary to integrate companies in the supply chain to obtain value from the stream of product returns. The most essential factor that can determine success is the coordination and incentive mechanism of the CLSC system.
In last several years, researchers have always been investigating CLSC system management. These studies mainly consist of three aspects of CLSC, including the investigation of the reverse logistics, price and return policy and coordination mechanism. From the aspect of the coordination and incentive mechanism, a coordination contract plays a crucial role. The wholesale price contract, two-part tariff contract, and reverse revenue sharing contract are most common. For example, Yan and Sun [10] found that a target rebate-punish may coordinate the reverse supply chain under the given conditions through the analysis of the closed form analytic expressions. Jing-Yan et al. [11] focused on how two-part tariff contracts could have different impacts on the retailer and manufacturer under both symmetric and asymmetric situations. More recent research has been conducted on the analysis of revenue sharing contracts such as [12-14]. Several types of contracts can coordinate the CLSC system by maximizing the participants' profit. Further research must be performed to investigate the differences between these contracts and determine whether they have the equal impacts on the CLSC system.

Therefore, the main contributions of this paper are comparing the different impacts of two types of contracts on the CLSC system under the same condition and determining which type should be selected from the perspective of the manufacturer. In this paper, we assume that the new and remanufactured products are wholesaled to retailers by manufacturers. At the same time, retailers sell these products in the market, collect used product from consumers, and sell these used products to the manufacturers. In this process, the manufacturer takes the leadership and the retailer acts as a follower.

This paper is structured as follows: Section 2 reviews the past literature on the coordination of CLSC. In Section 3, we introduce the key assumptions and notations that are used in the following sections; then we build the models for three conditions and resolve them in Section 4. Finally, we perform a numerical study and draw the conclusions.

\section{Literature Review}

In the last decade, there has been an enormous amount of research about CLSC. In the term of reverse logistics and network design, for example, [15] discussed several different CLSC scenarios based on the real case of German end-of-life vehicles (ELV) and introduced a problem-tailored algorithm; [16] studied how to make better CLSC network design for durable products with a mixed-integer programming model, taking the long life cycle of durable products and legislative target for recovery activities into consideration; on the topic of price and return policy, [17] established four game models to resolve the price decision problem and explore the role of manufacturer and the retailer in a CLSC system under symmetric and asymmetric information structures. Besides, [18] investigated how to design pricing and return policies when various supply contracts are applied in a CLSC system, where the supplier has more bargaining power. Reference [19] developed mathematical models based on different cases to study cooperation and competition issues in a CLSC, which 
comprises of two manufactures and one common retailer. At the same time, there are also abundant researches in the field of supply chain coordination. As the suggestion made by Arshinder et al. [20], the supply chain coordination could be achieved by four different coordination mechanisms, namely, coordination contracts, information technology, information sharing, and joint decision making. Among those four mechanisms, contract is an effective method that provides all of members in a decentralized supply chain with incentives, such as the optimization of the profit and minimization of inventory related costs, so that the decision maker can force participants to behave more cooperatively. Reference [14] presented an overview of contracting literature and suggested a classification of different coordination contracts. Based on the summary made by [14], the coordination contracts consist of wholesale price, revenue-sharing, buyback, quantity flexibility, sales rebate, quantity discount, backup, two-part tariff contracts, and so forth. And researches about forward coordination contracts have been conducted for a long time. For example, [13] investigated the scenario under a consignment arrangement with revenue-sharing contract, in which the supplier decides the retail price and delivery quantity and retains the ownership of the goods; [21] focused on the coordination contract of decentralized assembly systems, where the direct and indirect competition force as well as the vertical interaction force have been taken into consideration; [22] explored the resultant equilibrium in components' delivery quantities with a revenue-sharing contract and a wholesale price contract in a decentralized supply chain, which contains one retailer and multiple suppliers; [23] compared wholesale price and revenue-sharing contracts and then found that the latter has a unique pure strategy Nash equilibrium.

The coordination contracts applied in the forward supply chain are also available in the reverse supply chain, because compared with the manufacturer, the retailer or the thirdparty service provider (3P) has the advantage due to their location in the supply chain. They can achieve high return rate much more easily than the manufacturer [24]. However, according to the research of Govindan et al. [25], coordination contracts which can be applied in the reverse supply chain are limited, including the two-part tariff contract, revenue sharing contract, and quantity discount contract. For example, [26] found that, in a decentralized decisionmaking system, the agent, who is closer to the customer, is the most efficient undertaker of production collection activity for the manufacturer and suggested that the manufacturer should provide the appropriate wholesale price contract to the retailer to maximize the overall channel profit; [27] suggested that the wholesale price contract could coordinate the CLSC which is impossible in traditional forward chain; [28] developed a CLSC model, which consists of one retailer, one collector, and one manufacturer, to examine the performance of different CLSC systems with different channel leaderships and suggested that the CLSC should be coordinated by different types of practical contracts according to the specific leadership patterns; [10] concluded that it was targeting rebatepunish, not the wholesale price contract, which can coordinate the reverse supply chain under the given conditions through the analysis of the closed form analytic expressions.
There are different types of contracts which can be applied into the supply chain coordination, and then the responsibility of the participants is to make the decision of which one is worth of implementing and designing the contract parameters so that both players are satisfied with the contractual terms. Game Theory analysis plays an essential role in the process of decision making. For example, [29] pointed out that "a contract is said to coordinate the supply chain if the set of supply chain optimal actions is a Nash equilibrium; that is, no firm has a profitable unilateral deviation from the set of supply chain optimal actions. Ideally, the optimal actions should also be a unique Nash equilibrium; otherwise, the firms may "coordinate" on a suboptimal set of actions"; [30] found the profit pie between supply participants through the bargaining models and opened avenues of subsequent research in applying cooperative Game Theory to supply chain management; [31] analyzed both price-dependent and leader-follower games to determine the Nash and Stackelberg equilibria in a multiplesupplier, single manufacturer supply chain; [32] investigated the specific supply chain which contains one manufacturer and two retailers while considering the customer market search behavior through the game theoretic analysis.

According to our review of previous literatures, two-part tariff and revenue-sharing contracts are the most common coordination approaches. Some researchers, for example, Jing-Yan et al. [11], have already investigated the performance of TTC in a CLSC under symmetric and asymmetric situations; [33] demonstrated that the revenue-sharing and quantity discount contracts are self-enforcing, which may provide manufacturers with the incentives to collect used products. Furthermore, they found that revenue-sharing contracts and discount contracts could reduce the double marginalization; [14] analyzed the decentralized reverse settings followed by revenue sharing contract coordination. Thus it can be seen that the two-part tariff and revenue-sharing contracts are the most common and effective approaches which can encourage members of the CLSC to accomplish collection activities.

Because of these two common types of contracts, it is natural for us to wonder whether they have equal effects on the reverse supply chain and which is the better choice. Although there are numerous studies on the performance of coordination contracts, the comparison between these two contracts is limited. From our perspective, it is important to compare them to provide a practical guidance to the decision maker in the CLSC. To the best of our knowledge, we are the first to compare the different impacts of the two coordination contracts within a CLSC using the Stackelberg Game model to determine which should be chosen in different situations. Through our investigation, we determine which contract performs better and which should be chosen under various situations, which is meaningful in practical application.

\section{Key Assumptions and Notations}

Consider a two-echelon closed-loop supply chain, including a manufacturer and a retailer. In one case, the manufacturer provides the retailer with a two-part tariff contract to integrate the retailer into the collection activities. According to 
the requirement of the contract, the retailer has to pay a fixed transfer payment to the manufacturer in order to acquire the right for the sale and the higher transfer collection price. At the same time, the retailer is also responsible for product collection activities. In return, the manufacturer should share parts of the cost caused by the reverse activities and pay the transfer collection price $P_{t}$ for unit of product returns to the retailer. $P_{t}$ is not a fixed but a variable price, related to the return rate $r, P_{t}=P_{r}+\delta r P_{r}$, which means that the higher the return rate is, the higher the $P_{t}$ is. In this calculation formula of $P_{t}, \delta$ is called the ratio of transfer collection price in this paper, a fixed ratio defined by the manufacturer in the contract, and it is also the decision variable of our models.

In the other case, the manufacturer provides the retailer with a reverse revenue sharing contract (RRSC) to integrate the retailer into the CLSC. According to the RRSC, the retailer has to pay a certain proportion of sales revenue to the manufacturer. And the manufacturer has to undertake the same proportion of cost caused by the collection activities. The $P_{t}$ and $\delta$ in this case are the same with their definitions in the former case.

For the sake of clarity, before the demonstration of assumptions, the following notations are shown in (Notations of Mathematical Model) and are used for the development of the mathematical models.

\section{Notations of Mathematical Model}

$D$ : demand for product (involving new and remanufactured product),

$P$ : unit sale price of product,

$P_{r}$ : unit collection price of used product paid to customers,

$\delta$ : the ratio of transfer collection price, which is paid to retailer,

$w$ : unit wholesale price of product,

$C_{m 1}$ : unit production cost for new product,

$C_{m 2}$ : unit production cost for remanufactured product,

$\Delta: C_{m 1}-C_{m 2}\left(C_{m 1}-C_{m 2} \geq 0\right)$,

$C_{r 0}$ : fixed collection cost, caused for the reverse activities,

$C_{r 1}$ : variable collection cost, caused for the collection effort of retailer,

$r_{0}$ : potential return rate, $r_{0} \geq 0$,

$r_{1}$ : collection effort sensitivity of return rate,

$e$ : collection effort of retailer,

$T$ : fixed transfer payment of retailer to manufacturer in the TTC,

$1-\lambda$ : reverse revenue sharing ratio in the RRSC,

$\Pi_{i}^{j}$ : profit of participant ( $i=M$ (manufacturer) or $R$ (retailer), $j=1,2$ or 3 , means models 1,2 , and 3 ).
Assumption 1. The return rate $r=r_{0}+e r_{1}, r \in[0,1]$, which means that the return rate and collection effort have a positive correlation. If the retailer devotes more effort to reverse activity, the return rate will increase.

Assumption 2. The volume of the used product collected by the retailer: $Q_{r}=\left(r_{0}+e r_{1}\right) D$.

Assumption 3. The total collection cost $C_{r}=C_{r 0}+e^{2} C_{r 1}$; that is, the total collection cost will increase more and more rapidly with the increase of collection effort.

Assumption 4. We assume that the manufacturer acts as a leader, and at the same time, the retailer acts as a follower in the Stackelberg Game, which means the manufacturer has relatively stronger bargaining power over the retailer and is able to make the decisions on contract terms and conditions.

During the process of Stackelberg Game, the manufacturer provides the retailer with the coordination contract at first, and then the retailer makes the decision of acceptance or not. Therefore, as the leader, the manufacturer sets the goal of the CLSC as maximizing his own profit, but constrained by the retailer's requirement about profit. Both the manufacturer and the retailer have equal accesses to the information within the CLSC.

Under this assumption, the manufacturer determines the ratio of the transfer collection price $\delta$, transfer payment $T$, and the ratio of reverse revenue sharing $1-\lambda$. However, we do not attempt to study the influence of $T$ and $1-\lambda$ on the CLSC; therefore, the decision variable for the manufacturer is only $\delta$.

Assumption 5. In the cooperative scenarios, in order to collect the used product more efficiently, the manufacturer has to pay unit transfer collection price $P_{t}$ to the retailer: $P_{t}=\left(1+\delta\left(r_{0}+e r_{1}\right)\right) P_{r}, 1 \geq \delta \geq 0$, so $P_{t}$ must be higher than $P_{r}$. At the same time, $\Delta$ must also be higher than $P_{t}$; if not, the manufacturer will suffer a loss from the reverse activities and choose noncoordination in the CLSC.

Assumption 6. By using the RRSC, the manufacturer shares part of the reverse revenue with retailer; the manufacturer is also supposed to share part of the collection cost with the retailer in the same ratio. The ratio cannot be changed once the contract has been implemented.

\section{Model Construction and Analysis}

We built mathematical models under the three conditions of noncontract, two-part tariff contract, and reverse revenue sharing contract.

4.1. Model 1: Noncontract. In this situation, the retailer is independent and has no coordinative relationship with the manufacturer. Used product is collected at a collection price $P_{r}$ by the retailer and is transferred to the manufacturer at a fixed transfer collection price $\overline{P_{t}}$, which should be decided by the manufacturer before collection activities. Their relationship is shown in Figure 1. And the problem 


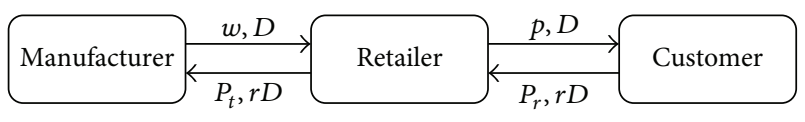

Figure 1: Model 1 under noncoordination contract.

for the retailer is how to determine the collection effort to maximize profit.

According to the above description, we can build the model:

$$
\begin{aligned}
\max _{\overline{\bar{P}_{t}}} & \Pi_{M}^{1}=\left(w-C_{m 1}\right) D-\left(\Delta-\overline{P_{t}}\right)\left(r_{0}+e r_{1}\right) D \\
\text { s.t. } & \max _{e} \Pi_{R}^{1} \\
= & (P-w) D+\left(\overline{P_{t}}-P_{r}\right)\left(r_{0}+e r_{1}\right) D-C_{r 0} \\
& -e^{2} C_{r 1} .
\end{aligned}
$$

The optimal collection effort level for retailer $e^{*}$ is determined by the first-order condition of the above function. The result is as follows:

$$
e^{*}=\frac{\left(\overline{P_{t}}-P_{r}\right) r_{1} D}{2 C_{r 1}}
$$

From this result, it is implied that the best collection effort for the retailer equals $\left(\left(\overline{P_{t}}-P_{r}\right) r_{1} D\right) / 2 C_{r 1}$, and it is clear to see that the higher the transfer collection price $\bar{P}_{t}$, the more the efforts the retailer would invest in the collection activities, which accords with the common sense.

4.2. Model 2: Two-Part Tariff Contract (TTC). If the manufacturer chooses TTC as the coordination method, then the retailer has to submit some fixed transfer payment $T$ to the manufacturer. As a reward, the manufacturer will pay transfer collection price $P_{t}$ for each unit of used product, which is shown in Figure 2.

In addition, $P_{t}$ is relevant to the return rate:

$$
P_{t}=\left(1+\delta\left(r_{0}+e r_{1}\right)\right) P_{r}, \quad \delta \geq 0
$$

which means the higher the return rate is, the higher the unit transfer collection price is. In this way, the retailer will obtain more profit from CLSC but will also devote more collection efforts.

The profits of manufacturer and retailer are formulated as follows:

$$
\begin{aligned}
\Pi_{M}^{2}= & \left(w-C_{m 1}\right) D+T \\
& +\left(\Delta-\left(1+\delta\left(r_{0}+e r_{1}\right)\right) P_{r}\right)\left(r_{0}+e r_{1}\right) D, \\
\Pi_{R}^{2}= & (p-w) D-T+\delta\left(r_{0}+e r_{1}\right)^{2} P_{r} D-C_{r 0} \\
& -e^{2} C_{r 1} .
\end{aligned}
$$

According to Assumption 1, the leader in this game is the manufacturer. Therefore, the manufacturer makes the decision of $\delta$ first, and the retailer obtains the decision of $e$ after observing the manufacturer's behavior. Therefore, we set the goal of this model as maximizing the manufacturer's profit, constrained by the optimization of the retailer's profit

$$
\begin{array}{ll}
\max _{\delta} & {\left[\left(w-C_{m 1}\right) D+T+\left(\Delta-\left(1+\delta\left(r_{0}+e r_{1}\right)\right) P_{r}\right)\left(r_{0}+e r_{1}\right) D\right]} \\
\text { s.t. } & \max _{e}\left[(p-w) D-T+\delta\left(r_{0}+e r_{1}\right)^{2} P_{r} D-C_{r 0}-e^{2} C_{r 1}\right] .
\end{array}
$$

By using backward induction, we can find the response function of the retailer, which is the first stage of the Stackelberg model:

$$
\frac{\partial \Pi_{R}^{2}}{\partial e}=2 \delta P_{r} D r_{1} r_{0}+2\left(\delta P_{r} D r_{1}^{2}-C_{r 1}\right) e .
$$

From the response function above, we can know that the retailer's profit and collection effort are in linear relation and the value of $\delta P_{r} D r_{1}^{2}-C_{r 1}$ determines whether the relationship of these two variables is positive or negative.

Then, the best response for the retailer $e^{*}$ can be concluded by solving the response function of the retailer:

$$
e^{*}=\frac{\delta P_{r} D r_{1} r_{0}}{C_{r 1}-\delta P_{r} D r_{1}^{2}} .
$$

According to Assumption 1: $r=r_{0}+e r_{1}$, we stipulate that the value of $e$ is positive in order to ensure that the return rate $r$ must be no less than the potential return rate $r_{0}$. Therefore, we get the inequality: $C_{r 1}-\delta P_{r} D r_{1}^{2}>0, \delta \in[0,1]$, which means $\delta<C_{r 1} / P_{r} D r_{1}^{2}$. In order to simplify the calculation, we stipulate that $C_{r 1} / P_{r} D r_{1}^{2}>1$, because $\delta \in[0,1]$.

Now, we can verify that the best response $e^{*}$ maximizes the retailer's profit through the secondary derivation:

$$
\frac{\partial \Pi_{R}^{2}}{\partial e^{2}}=-\left(2 C_{r 1}-2 \delta D P_{r} r_{1}^{2}\right)=-2\left(C_{r 1}-\delta D P_{r} r_{1}^{2}\right) .
$$

Because of the inequality: $C_{r 1}-\delta P_{r} D r_{1}^{2}>0, \delta \in[0,1]$, the value of the $\partial \Pi_{R}^{2} / \partial e^{2}$ must be negative, which means that the graph of function (5) is convex and there is a vertex for the retailer's profit: $\Pi_{R}^{2}$. 


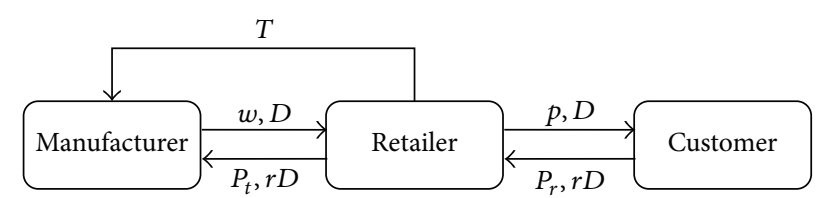

FIgure 2: Model 2 under TTC.
To obtain the response function of the manufacturer, we insert formula (8) into the function of manufacturer's profit:

$$
\begin{aligned}
\Pi_{M}^{2}= & \left(w-C_{m 1}\right) D+T \\
& +\left(\Delta-\left(1+\delta\left(r_{0}+e^{*} r_{1}\right)\right) P_{r}\right)\left(r_{0}+e^{*} r_{1}\right) D .
\end{aligned}
$$

Before calculating the response function, we verify that there exists a maximum manufacturer profit using the secondary derivation:

$$
\frac{\partial \Pi_{M}^{2}{ }^{2}}{\partial \delta^{2}}=-2 C_{r 1} D^{2} P_{r}^{2} r_{0} r_{1}^{2} \frac{2 C_{r 1}^{2} r_{0}-\left(\Delta-P_{r}\right) D C_{r 1} r_{1}^{2}+\delta\left[D^{2} P_{r} r_{1}^{4}\left(\Delta-P_{r}\right)+C_{r 1} D P_{r} r_{1}^{2} r_{0}\right]}{\left(C_{r 1}-\delta D P_{r} r_{1}^{2}\right)^{4}} .
$$

We have already known the inequality: $C_{r 1}-\delta P_{r} D r_{1}^{2}>0$, $\delta \in[0,1]$ and that the value of $-2 C_{r 1} D^{2} P_{r}^{2} r_{0} r_{1}^{2}$ is negative constantly. Therefore, the value of $\partial \Pi_{M}^{2} / \partial \delta^{2}$ being positive or negative depends on the value of $2 C_{r 1}^{2} r_{0}-\left(\Delta-P_{r}\right) D C_{r 1} r_{1}^{2}$.

Scenario $1\left(2 C_{r 1}^{2} r_{0}-\left(\Delta-P_{r}\right) D C_{r 1} r_{1}^{2} \geq 0\right)$. If $2 C_{r 1}^{2} r_{0}-(\Delta-$ $\left.P_{r}\right) D C_{r 1} r_{1}^{2} \geq 0$, then the graph of $\partial \Pi_{M}^{2}{ }^{2} / \partial \delta^{2}$ will be as shown in Figure 3.
By expanding the size of Figure 3, we can see that the value of the second derivative of manufacturer's profit function is always negative within the interval $\delta \in[0,1]$.

What's more, we can get the following function:

$$
\frac{\partial \Pi_{M}^{2}}{\partial \delta}=-C_{r 1} D P_{r} r_{0} \frac{C_{r 1}^{2} r_{0}-\left(\Delta-P_{r}\right) D C_{r 1} r_{1}^{2}+\delta\left[D^{2} P_{r} r_{1}^{4}\left(\Delta-P_{r}\right)+C_{r 1} D P_{r} r_{1}^{2} r_{0}\right]}{\left(C_{r 1}-\delta D P_{r} r_{1}^{2}\right)^{3}} .
$$

According to Figure 3 and function (12), the value of $\partial \Pi_{M}^{2} / \partial \delta$ will decrease as ratio of transfer collection price $\delta$, $\delta \in[0,1]$, increases. Therefore, there are three possibilities: first, the value of $\partial \Pi_{M}^{2} / \partial \delta$ is always positive within the interval $\delta \in[0,1]$; second, it is always negative within $\delta \in$ $[0,1]$; in the last one, it is positive at first and then falls down below 0 .

From the above analysis, it is assertive that the graph's shape of function (12) depends on the exact values of $\partial \Pi_{M}^{2} / \partial \delta$. Concretely, it depends on the value of $C_{r 1}^{2} r_{0}-(\Delta-$ $\left.P_{r}\right) D C_{r 1} r_{1}^{2}$ :

(1) $C_{r 1}^{2} r_{0}-\left(\Delta-P_{r}\right) D C_{r 1} r_{1}^{2}>0$. When $\delta=0,\left(\partial \Pi_{M}^{2} /\right.$ $\partial \delta)\left.\right|_{\delta=0}=-C_{r 1} D P_{r} r_{0}\left(\left(C_{r 1}^{2} r_{0}-\left(\Delta-P_{r}\right) D C_{r 1} r_{1}^{2}\right) / C_{r 1}^{3}\right)<$ 0 ; therefore, we know that the values of $\partial \Pi_{M}^{2} / \partial \delta$, $\delta \in[0,1]$ will be always negative. Additionally, the manufacturer's profit will decrease as $\delta, \delta \in[0,1]$, increases.

(2) $C_{r 1}^{2} r_{0}-\left(\Delta-P_{r}\right) D C_{r 1} r_{1}^{2}<0$. Similarly, $\left.\left(\partial \Pi_{M}^{2} / \partial \delta\right)\right|_{\delta=0}$ $=-C_{r 1} D P_{r} r_{0}\left(\left(C_{r 1}^{2} r_{0}-\left(\Delta-P_{r}\right) D C_{r 1} r_{1}^{2}\right) / C_{r 1}^{3}\right)>0$, and

$$
\left.\frac{\partial \Pi_{M}^{2}}{\partial \delta}\right|_{\delta=1}=-C_{r 1} D P_{r} r_{0}
$$

$$
\begin{aligned}
& \cdot \frac{C_{r 1}^{2} r_{0}-\left(\Delta-P_{r}\right) D C_{r 1} r_{1}^{2}+D^{2} P_{r} r_{1}^{4}\left(\Delta-P_{r}\right)+C_{r 1} D P_{r} r_{1}^{2} r_{0}}{\left(C_{r 1}-D P_{r} r_{1}^{2}\right)^{3}} \\
& =\frac{C_{r 1}^{2} r_{0}+C_{r 1} D P_{r} r_{1}^{2} r_{0}+\left(\Delta-P_{r}\right) D r_{1}^{2}\left(D P_{r} r_{1}^{2}-C_{r 1}\right)}{\left(C_{r 1}-D P_{r} r_{1}^{2}\right)^{3}} .
\end{aligned}
$$

Because of the inequity: $C_{r 1}-\delta P_{r} D r_{1}^{2}>0, \delta \in[0,1]$, we cannot make sure that if the value of $\left.\left(\partial \Pi_{M}^{2} / \partial \delta\right)\right|_{\delta=1}$ is negative or positive.

Therefore, if $C_{r 1}^{2} r_{0}+C_{r 1} D P_{r} r_{1}^{2} r_{0}+\left(\Delta-P_{r}\right) D r_{1}^{2}\left(D P_{r} r_{1}^{2}-\right.$ $\left.C_{r 1}\right)>0$, the manufacturer's profit will increase as $\delta, \delta \in$ $[0,1]$, increases.

If not, then there is a maximum of manufacturer's profit, which means there is an optimal choice of $\delta$ for manufacturer.

In order to find the optimal value of $\delta$, make the function (12) equal to 0 , and then

$$
\delta^{*}=\frac{\left(\Delta-P_{r}\right) D C_{r 1} r_{1}^{2}-C_{r 1}^{2} r_{0}}{D^{2} P_{r} r_{1}^{4}\left(\Delta-P_{r}\right)+C_{r 1} D P_{r} r_{1}^{2} r_{0}} .
$$

Scenario $2\left(2 C_{r 1}^{2} r_{0}-\left(\Delta-P_{r}\right) D C_{r 1} r_{1}^{2}<0\right)$. Similarly, if $2 C_{r 1}^{2} r_{0}-$ $\left(\Delta-P_{r}\right) D C_{r 1} r_{1}^{2}<0$, the graph of $\partial \Pi_{M}^{2} / \partial \delta^{2}$ could be drawn in Figure 4. 


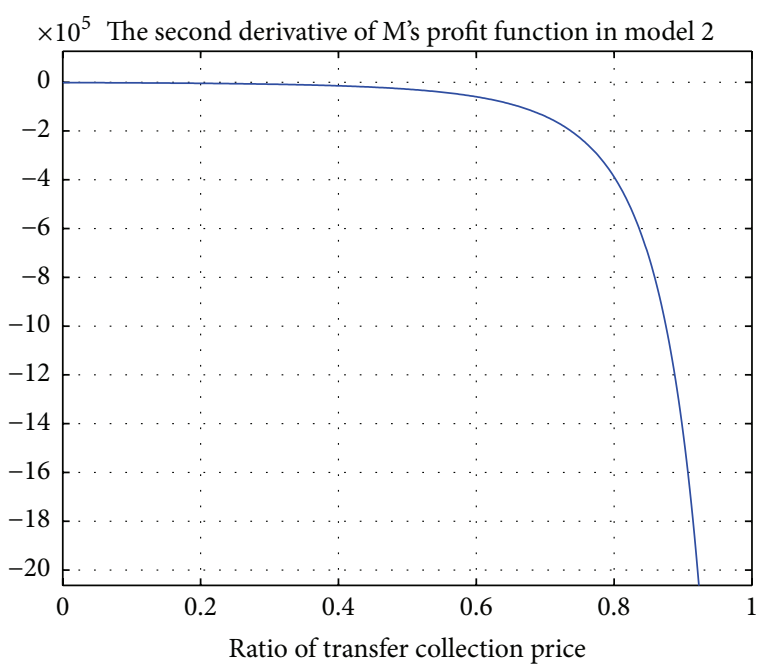

Figure 3: The graph of $\partial \Pi_{M}^{2}{ }^{2} / \partial \delta^{2} . \Delta=40, C_{r 1}=50, P_{r}=29.57, D=$ $573.91, r_{1}=0.05, r_{0}=0.25$ satisfy the inequality $C_{r 1}-\delta P_{r} D r_{1}^{2}>0$, $\delta \in[0,1]$.

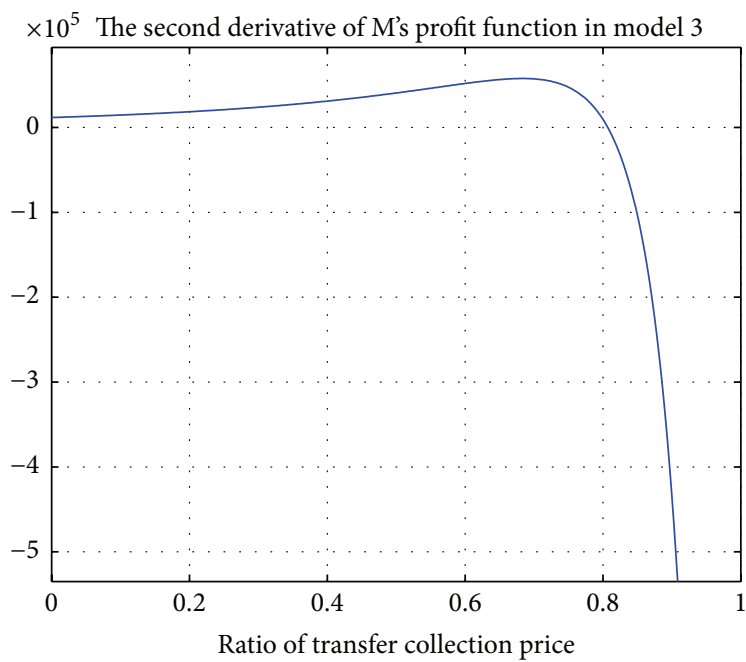

FIGURE 4: The graph of $\partial \Pi_{M}^{2}{ }^{2} / \partial \delta^{2} . \Delta=103.78, C_{r 1}=50, P_{r}=29.57$, $D=573.91, r_{1}=0.05, r_{0}=0.25$ satisfy the inequality $C_{r 1}-\delta P_{r} D r_{1}^{2}>$ $0, \delta \in[0,1]$.

From the graphs and function (12), we know that the value of $\partial \Pi_{M}^{2} / \partial \delta$ will increase at first and then start to decrease at a certain point of $\delta$. Therefore, there is a maximum of the value of $\partial \Pi_{M}^{2} / \partial \delta$.

In order to get more information about the graph of function (12), we have to discuss further the following:

Since $2 C_{r 1}^{2} r_{0}-\left(\Delta-P_{r}\right) D C_{r 1} r_{1}^{2}<0$, then $C_{r 1}^{2} r_{0}-(\Delta-$ $\left.P_{r}\right) D C_{r 1} r_{1}^{2}=2 C_{r 1}^{2} r_{0}-\left(\Delta-P_{r}\right) D C_{r 1} r_{1}^{2}<0$.

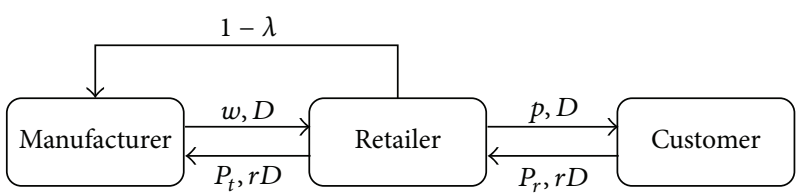

FIgURE 5: Model 3 under RRSC.

$$
\left.\left(\partial \Pi_{M}^{2} / \partial \delta\right)\right|_{\delta=0}=-C_{r 1} D P_{r} r_{0}\left(\left(C_{r 1}^{2} r_{0}-\left(\Delta-P_{r}\right) D C_{r 1} r_{1}^{2}\right) /\right.
$$$$
\left.C_{r 1}^{3}\right)>0 \text {, and }
$$

$$
\begin{aligned}
& \left.\frac{\partial \Pi_{M}^{2}}{\partial \delta}\right|_{\delta=1}=-C_{r 1} D P_{r} r_{0} \\
& . \frac{C_{r 1}^{2} r_{0}-\left(\Delta-P_{r}\right) D C_{r 1} r_{1}^{2}+D^{2} P_{r} r_{1}^{4}\left(\Delta-P_{r}\right)+C_{r 1} D P_{r} r_{1}^{2} r_{0}}{\left(C_{r 1}-D P_{r} r_{1}^{2}\right)^{3}} \\
& =-C_{r 1} D P_{r} r_{0} \\
& . \frac{C_{r 1}^{2} r_{0}+C_{r 1} D P_{r} r_{1}^{2} r_{0}+\left(\Delta-P_{r}\right) D r_{1}^{2}\left(D P_{r} r_{1}^{2}-C_{r 1}\right)}{\left(C_{r 1}-D P_{r} r_{1}^{2}\right)^{3}} .
\end{aligned}
$$

It is for sure that the value of $\left.\left(\partial \Pi_{M}^{2} / \partial \delta\right)\right|_{\delta=1}$ being negative or positive depends on the value of numerator:

(1) $C_{r 1}^{2} r_{0}-\left(\Delta-P_{r}\right) D C_{r 1} r_{1}^{2}+D^{2} P_{r} r_{1}^{4}\left(\Delta-P_{r}\right)+C_{r 1} D P_{r} r_{1}^{2} r_{0}>$ 0 . The value of $\left.\left(\partial \Pi_{M}^{2} / \partial \delta\right)\right|_{\delta=1}$ is negative, which means the manufacturer's profit will grow as the growth of $\delta$ at first and then start to decrease at a certain level:

$$
\delta^{*}=\frac{\left(\Delta-P_{r}\right) D C_{r 1} r_{1}^{2}-C_{r 1}^{2} r_{0}}{D^{2} P_{r} r_{1}^{4}\left(\Delta-P_{r}\right)+C_{r 1} D P_{r} r_{1}^{2} r_{0}} .
$$

(2) $C_{r 1}^{2} r_{0}-\left(\Delta-P_{r}\right) D C_{r 1} r_{1}^{2}+D^{2} P_{r} r_{1}^{4}\left(\Delta-P_{r}\right)+C_{r 1} D P_{r} r_{1}^{2} r_{0}<$ 0 . The value of $\left.\left(\partial \Pi_{M}^{2} / \partial \delta\right)\right|_{\delta=1}$ is positive, which means the manufacturer's profit will always grow within the interval: $\delta \in[0,1]$.

Proposition 7. Only under the certain conditions, there is an optimal choice of $\delta, \delta \in[0,1]$, for the manufacturer to maximize its profit:

$$
\delta^{*}=\frac{\left(\Delta-P_{r}\right) D C_{r 1} r_{1}^{2}-C_{r 1}^{2} r_{0}}{D^{2} P_{r} r_{1}^{4}\left(\Delta-P_{r}\right)+C_{r 1} D P_{r} r_{1}^{2} r_{0}} .
$$

Therefore, we drew out the conclusion that the manufacturer could maximize its profit from the CLSC system by adjusting $\delta, \delta \in[0,1]$, stipulated in the two-part tariff contract, only under the specific conditions. Nevertheless, under other conditions, the manufacturer can simply make $\delta=0 / 1$, because, within the interval of $\delta \in[0,1]$, the manufacturer's profit will just decrease or increase all the time.

4.3. Model 3: Reverse Revenue Sharing Contract (RRSC). By using RRSC as the coordination method, the manufacturer and retailer have to share the collection cost and sales revenue, which is shown in Figure 5. 
The profit of the manufacturer is composed of the wholesale revenue, the saving cost from remanufacturing the used product, and the sharing part from the retailer; meanwhile, the manufacturer has to pay some part of the collection cost incurred during the reverse activities. These costs are shown in the following formulation:

$$
\begin{aligned}
\Pi_{M}^{3}= & \left(w-C_{m 1}\right) D+(1-\lambda)(p-w) D \\
& +\left(\Delta-\left(1+\delta\left(r_{0}+e r_{1}\right)\right) P_{r}\right)\left(r_{0}+e r_{1}\right) D \\
& -(1-\lambda)\left(C_{r 0}+e^{2} C_{r 1}\right) .
\end{aligned}
$$

The profit of the retailer can be transformed into a mathematical formulation:

$$
\begin{aligned}
\Pi_{R}^{3}= & \lambda(p-w) D+\delta\left(r_{0}+e r_{1}\right)^{2} P_{r} D \\
& -\lambda\left(C_{r 0}+e^{2} C_{r 1}\right)
\end{aligned}
$$

In the same way, the model under RRSC can be built:

$$
\begin{aligned}
\max _{\delta} & \left\{\left(w-C_{m 1}\right) D+(1-\lambda)(p-w) D+\left[\Delta-\left(1+\delta\left(r_{0}+e r_{1}\right)\right) P_{r}\right]\left(r_{0}+e r_{1}\right) D-(1-\lambda)\left(C_{r 0}+e^{2} C_{r 1}\right)\right\} \\
\text { s.t. } & \max _{e}\left\{\lambda(p-w) D+\delta\left(r_{0}+e r_{1}\right)^{2} P_{r} D-\lambda\left(C_{r 0}+e^{2} C_{r 1}\right)\right\} .
\end{aligned}
$$

First, we find the reaction function of the retailer according to the first-order condition:

$$
\frac{\partial \Pi_{R}^{3}}{\partial e}=2 \delta P_{r} D r_{1} r_{0}+2\left(\delta P_{r} D r_{1}^{2}-\lambda C_{r 1}\right) e
$$

Based on the above formula, we obtain the best response for the retailer:

$$
e^{*}(\delta)=\frac{\delta P_{r} D r_{1} r_{0}}{\lambda C_{r 1}-\delta P_{r} D r_{1}^{2}}
$$

Because of the same reason in model 2, we stipulate that

$$
\lambda C_{r 1}-\delta P_{r} D r_{1}^{2}>0
$$

Function (23) equals the following inequality $\delta<$ $\lambda C_{r 1} / P_{r} D r_{1}^{2}$. Same as model 2 , in order to simplify the calculation, we assume that $1<\lambda C_{r 1} / P_{r} D r_{1}^{2}$, because $\delta \in$ $[0,1]$.
Then, we verify that $e^{*}(\delta)$ maximizes the retailer's profit by taking the second derivative:

$$
\frac{\partial \Pi_{R}^{2}}{\partial e^{2}}=-2\left(\lambda C_{r 1}-\delta D P_{r} r_{1}^{2}\right)
$$

The value of $\partial \Pi_{R}^{2} / \partial^{2} e$ must be negative because $\lambda C_{r 1}-$ $\delta P_{r} D r_{1}^{2}>0$. Therefore, the best response $e^{*}(\delta)$ maximizes the retailer's profit.

Next, $e^{*}(\delta)$ is inserted into the function of the manufacturer's profit to obtain the reaction function:

$$
\begin{aligned}
& \Pi_{M}^{3}=\left[\left(w-C_{m 1}\right) D+(1-\lambda)(p-w) D\right. \\
& \left.\quad+\left(\Delta-\left(1+\delta\left(r_{0}+e^{*} r_{1}\right)\right) P_{r}\right)\left(r_{0}+e^{*} r_{1}\right) D\right]-(1 \\
& \quad-\lambda)\left(C_{r 0}+e^{2} C_{r 1}\right) .
\end{aligned}
$$

Similarly, we verify that there exists a best response for the manufacturer by taking the second derivative:

$$
\begin{aligned}
\frac{\partial \Pi_{M}^{32}}{\partial \delta^{2}} & =-2 \lambda C_{r 1} D^{2} P_{r}^{2} r_{0} r_{1}^{2} \frac{\lambda(1+\lambda) C_{r 1}^{2} r_{0}+(2-\lambda) \delta C_{r 1} D P_{r} r_{0} r_{1}^{2}+\left(\Delta-P_{r}\right) D r_{1}^{2}\left(\delta D P_{r} r_{1}^{2}-\lambda C_{r 1}\right)}{\left(\lambda C_{r 1}-\delta D P_{r} r_{1}^{2}\right)^{4}} \\
& =-2 \lambda C_{r 1} D^{2} P_{r}^{2} r_{0} r_{1}^{2} \frac{\lambda(1+\lambda) C_{r 1}^{2} r_{0}-\left(\Delta-P_{r}\right) \lambda C_{r 1} D r_{1}^{2}+\delta\left[(2-\lambda) C_{r 1} D P_{r} r_{0} r_{1}^{2}+\left(\Delta-P_{r}\right) D^{2} P_{r} r_{1}^{4}\right]}{\left(\lambda C_{r 1}-\delta D P_{r} r_{1}^{2}\right)^{4}}
\end{aligned}
$$

It is for sure that the value of $-2 \lambda C_{r 1} D^{2} P_{r}^{2} r_{0} r_{1}^{2}$ must be negative and the value of $\left(\lambda C_{r 1}-\delta D P_{r} r_{1}^{2}\right)^{4}$ must be positive. Consequently, that the value of $\partial \Pi_{M}^{3}{ }^{2} / \partial \delta^{2}$ is negative or positive depends on $\lambda(1+\lambda) C_{r 1}^{2} r_{0}-\left(\Delta-P_{r}\right) \lambda C_{r 1} D r_{1}^{2}$.

Scenario $3\left(\lambda(1+\lambda) C_{r 1}^{2} r_{0}-\left(\Delta-P_{r}\right) \lambda C_{r 1} D r_{1}^{2} \geq 0\right)$. Under this condition, within the interval of $\delta \in[0,1]$, the value of $\partial \Pi_{M}^{3}{ }^{2} / \partial \delta^{2}$ must be negative, because $\left.\left(\partial \Pi_{M}^{3}{ }^{2} / \partial \delta^{2}\right)\right|_{\delta=0}=$ $-2 \lambda C_{r 1} D^{2} P_{r}^{2} r_{0} r_{1}^{2}\left(\lambda(1+\lambda) C_{r 1}^{2} r_{0}-\left(\Delta-P_{r}\right) \lambda D C_{r 1} r_{1}^{2}\right) /\left(\lambda C_{r 1}\right)^{4}>$ 0 and the value of the numerator will increase as the growth of $\delta$. It means the value of $\partial \Pi_{M}^{3} / \partial \delta$ will decrease as $\delta$ increases.

Next, in order to study the trend of manufacturer's profit, we should discuss more the following: 


$$
\frac{\partial \Pi_{M}^{3}}{\partial \delta}=-\lambda C_{r 1} D P_{r} r_{0} \frac{\lambda^{2} C_{r 1}^{2} r_{0}-\left(\Delta-P_{r}\right) \lambda C_{r 1} D r_{1}^{2}+\delta\left[(2-\lambda) C_{r 1} D P_{r} r_{0} r_{1}^{2}+\left(\Delta-P_{r}\right) D^{2} P_{r} r_{1}^{4}\right]}{\left(\lambda C_{r 1}-\delta D P_{r} r_{1}^{2}\right)^{3}} .
$$

(1) $\lambda^{2} C_{r 1}^{2} r_{0}-\left(\Delta-P_{r}\right) \lambda C_{r 1} D r_{1}^{2} \geq 0$. Since $\left.\left(\partial \Pi_{M}^{3} / \partial \delta\right)\right|_{\delta=0}=$ $-\lambda C_{r 1} D P_{r} r_{0}\left(\left(\lambda^{2} C_{r 1}^{2} r_{0}-\left(\Delta-P_{r}\right) \lambda D C_{r 1} r_{1}^{2}\right) /\left(\lambda C_{r 1}\right)^{3}\right) \leq$ 0 and the value of $\partial \Pi_{M}^{3} / \partial \delta$ will decrease as the growth of $\delta, \partial \Pi_{M}^{3} / \partial \delta$ must be negative within the interval of $\delta \in[0,1]$, which means the manufacturer's profit is supposed to decrease with the increase of $\delta$.

(2) $\lambda^{2} C_{r 1}^{2} r_{0}-\left(\Delta-P_{r}\right) \lambda C_{r 1} D r_{1}^{2}<0 .\left.\left(\partial \Pi_{M}^{3} / \partial \delta\right)\right|_{\delta=0}=$ $-\lambda C_{r 1} D P_{r} r_{0}\left(\left(\lambda^{2} C_{r 1}^{2} r_{0}-\left(\Delta-P_{r}\right) \lambda D C_{r 1} r_{1}^{2}\right) /\left(\lambda C_{r 1}\right)^{3}\right)>$ 0 and the value of

$$
\left.\frac{\partial \Pi_{M}^{3}}{\partial \delta}\right|_{\delta=1}=-\lambda C_{r 1} D P_{r} r_{0} \frac{\lambda^{2} C_{r 1}^{2} r_{0}-\left(\Delta-P_{r}\right) \lambda D C_{r 1} r_{1}^{2}+\left(\Delta-P_{r}\right) D^{2} P_{r} r_{1}^{4}+(2-\lambda) C_{r 1} D P_{r} r_{0} r_{1}^{2}}{\left(\lambda C_{r 1}\right)^{3}}
$$

There are two possibilities for the value of $\left.\left(\partial \Pi_{M}^{3} / \partial \delta\right)\right|_{\delta=1}$ :

(1) $\lambda^{2} C_{r 1}^{2} r_{0}-\left(\Delta-P_{r}\right) \lambda D C_{r 1} r_{1}^{2}+\left(\Delta-P_{r}\right) D^{2} P_{r} r_{1}^{4}+(2-$ d) $C_{r 1} D P_{r} r_{0} r_{1}^{2} \geq 0$. Under this condition, the value of $\partial \Pi_{M}^{3} / \partial \delta$ is always positive within the interval $\delta \epsilon$ $[0,1]$, which means the manufacturer's profit should increase as $\delta$ increases.

(2) $\lambda^{2} C_{r 1}^{2} r_{0}-\left(\Delta-P_{r}\right) \lambda D C_{r 1} r_{1}^{2}+\left(\Delta-P_{r}\right) D^{2} P_{r} r_{1}^{4}+(2-$ d) $C_{r 1} D P_{r} r_{0} r_{1}^{2}<0$. Otherwise, there is an optimal choice of $\delta$ for the manufacturer, which can maximize its profit

$$
\delta^{*}=\frac{\lambda\left(\Delta-P_{r}\right) D C_{r 1} r_{1}^{2}-\lambda^{2} C_{r 1}^{2} r_{0}}{(2-\lambda) D C_{r 1} P_{r} r_{0} r_{1}^{2}+\left(\Delta-P_{r}\right) D^{2} P_{r} r_{1}^{4}} .
$$

Scenario $4\left(\lambda(1+\lambda) C_{r 1}^{2} r_{0}-\left(\Delta-P_{r}\right) \lambda C_{r 1} D r_{1}^{2}<0\right)$. Under this condition, the value of $\partial \Pi_{M}^{3} / \partial \delta$ will increase at first and then decrease as the growth of $\delta$. Consequently, in order to get more information about the trend of $\partial \Pi_{M}^{3} / \partial \delta$ and the manufacturer's profit, we should make further analysis about $\partial \Pi_{M}^{3} / \partial \delta$.

Since $\lambda(1+\lambda) C_{r 1}^{2} r_{0}-\left(\Delta-P_{r}\right) \lambda C_{r 1} D r_{1}^{2}<0$, then $\lambda^{2} C_{r 1}^{2} r_{0}-\left(\Delta-P_{r}\right) \lambda C_{r 1} D r_{1}^{2}<0$, because $\lambda \in[0,1]$. Therefore, $\left.\left(\partial \Pi_{M}^{3} / \partial \delta\right)\right|_{\delta=0}=-\lambda C_{r 1} D P_{r} r_{0}\left(\left(\lambda^{2} C_{r 1}^{2} r_{0}-(\Delta-\right.\right.$ $\left.\left.\left.P_{r}\right) \lambda D C_{r 1} r_{1}^{2}\right) /\left(\lambda C_{r 1}\right)^{3}\right)>0$.

Additionally,

$$
\left.\frac{\partial \Pi_{M}^{3}}{\partial \delta}\right|_{\delta=1}=-\lambda C_{r 1} D P_{r} r_{0} \frac{\lambda^{2} C_{r 1}^{2} r_{0}-\left(\Delta-P_{r}\right) \lambda D C_{r 1} r_{1}^{2}+\left(\Delta-P_{r}\right) D^{2} P_{r} r_{1}^{4}+(2-\lambda) C_{r 1} D P_{r} r_{0} r_{1}^{2}}{\left(\lambda C_{r 1}\right)^{3}}
$$

Make $B=\lambda^{2} C_{r 1}^{2} r_{0}-\left(\Delta-P_{r}\right) \lambda D C_{r 1} r_{1}^{2}+\left(\Delta-P_{r}\right) D^{2} P_{r} r_{1}^{4}+$ $(2-\lambda) C_{r 1} D P_{r} r_{0} r_{1}^{2}$.

(1) $\lambda^{2} C_{r 1}^{2} r_{0}-\left(\Delta-P_{r}\right) \lambda D C_{r 1} r_{1}^{2}+\left(\Delta-P_{r}\right) D^{2} P_{r} r_{1}^{4}+(2-$ d) $C_{r 1} D P_{r} r_{0} r_{1}^{2}<0$. If $B<0$, then the manufacturer's profit will increase all the time.

(2) $\lambda^{2} C_{r 1}^{2} r_{0}-\left(\Delta-P_{r}\right) \lambda D C_{r 1} r_{1}^{2}+\left(\Delta-P_{r}\right) D^{2} P_{r} r_{1}^{4}+(2-$ d) $C_{r 1} D P_{r} r_{0} r_{1}^{2} \geq 0$. Otherwise, there is a certain level of $\delta$, which could maximize the manufacturer's profit:

$$
\delta^{*}=\frac{\lambda\left(\Delta-P_{r}\right) D C_{r 1} r_{1}^{2}-\lambda^{2} C_{r 1}^{2} r_{0}}{(2-\lambda) D C_{r 1} P_{r} r_{0} r_{1}^{2}+\left(\Delta-P_{r}\right) D^{2} P_{r} r_{1}^{4}} .
$$

Proposition 8. Similarly, for model 3, there is an optimal choice of $\delta, \delta \in[0,1]$ for the manufacturer to maximize its profit:

$$
\delta^{*}=\frac{\lambda\left(\Delta-P_{r}\right) D C_{r r} r_{1}^{2}-\lambda^{2} C_{r 1}^{2} r_{0}}{(2-\lambda) D C_{r 1} P_{r} r_{0} r_{1}^{2}+\left(\Delta-P_{r}\right) D^{2} P_{r} r_{1}^{4}} .
$$

Consequently, we could draw out the similar conclusion as model 2 that the manufacturer could maximize its profit from the CLSC system by adjusting $\delta, \delta \in[0,1]$, stipulated in the RRSC, only under the specific conditions. Nevertheless, under other conditions, the manufacturer can simply make $\delta=0 / 1$, because, within the interval of $\delta \in[0,1]$, the manufacturer's profit will just decrease or increase all the time. 


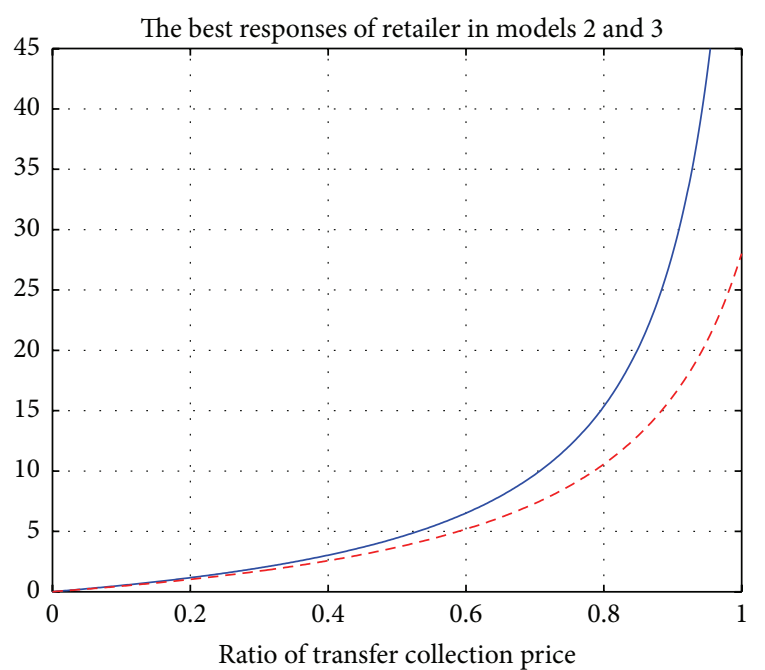

- Model 3

- - Model 2

Figure 6: Comparison of the effort level between two models.

The optimal response functions, $\delta^{*}=\left(\left(\Delta-P_{r}\right) D C_{r 1} r_{1}^{2}-\right.$ $\left.C_{r 1}^{2} r_{0}\right) /\left(D^{2} P_{r} r_{1}^{4}\left(\Delta-P_{r}\right)+C_{r 1} D P_{r} r_{1}^{2} r_{0}\right)$ (under the two-part tariff contract $)$ and $\delta^{*}=\left(\lambda\left(\Delta-P_{r}\right) D C_{r 1} r_{1}^{2}-\lambda^{2} C_{r 1}^{2} r_{0}\right) /((2-$ 1)DC $\left.{ }_{r 1} P_{r} r_{0} r_{1}^{2}+\left(\Delta-P_{r}\right) D^{2} P_{r} r_{1}^{4}\right)$ (under the reverse revenuesharing contract), are complex, not mention taking them into the manufacturer's profit function. Therefore, we investigate different effects of two kinds of contract on the manufacturer, retailer, and the whole closed-loop supply chain through the numerical analysis.

\section{Numerical Analysis}

According to the conclusion shown in Tables 1 and 2, we have known the best choices of $\delta$ under different conditions. Now we tend to verify the authenticity of our conclusion by making further numerical simulation.

First, we assign all of the variables as shown in Table 3.

After taking all of given variables into formulas in Tables 1 and 2, it is clear that our case belongs to the condition 2-1-1, shown in Tables 1 and 2. So it is certain that there exist maximum profits for the manufacturer in both models 2 and 3.

Next, we verify our findings in the previous section by making a numerical analysis. At first, we draw the curve of the retailer's best responses in models 2 and 3 by MATLAB in Figure 6.

Conclusion 1. Figure 4 shows that the best collection effort $e^{*}$ for the retailer is relevant to the ratio of the transfer collection price $\delta$, designed by the manufacturer. The higher the ratio is, the higher the effort level would be. If the manufacturer wants the retailer to devote more effort, he can increase $\delta$ under both types of contracts. In addition, the marginal effort level is raised with the improvement of the ratio. Meanwhile, the return rate will increase because the return rate is positively related to the effort level of the retailer. The manufacturer can raise the return rate by raising the ratio of the transfer collection price. What is more important is that the reverse revenue-sharing contract will help the manufacturer to encourage the retailer to put more efforts into the collection activities with the same ratio of the collection transfer price $\delta$ in the two-part tariff contract.

Additionally, we can obtain Figure 7 that depicts the change of the retailer's profit at $e^{*}$ with the change of $\delta$ in models 2 and 3:

As Figure 7 shows, the relationships between the retailer's profit at $e^{*}$ and the ratio $\delta$ are very similar in both two models: the retailer's profits will always increase as the growth of $\delta$. What is more, under given variables, the retailer in model 3 could get profit more than that in model 2 at the same level of $\delta$.

Conclusion 2. The two types of coordination contracts have similar impacts on the retailer's profit. Under both TTC and RRSC, the retailer's profit will increase if the manufacturer raises the ratio of the transfer collection price and as the growth of $\delta$, the retailer's profit grows faster, which means the higher the ratio is, the more the retailer's profit is.

The determinant element in the process of deciding the contract type is the profit of the manufacturer. The manufacturer will choose the contract which can bring more profit. Consequently, it is necessary to calculate the precise profits under the two conditions. Figure 8 shows the specific simulation results of the manufacturer's profit.

Just as our analysis, under the given variables, there exists an optimal $\delta$ which can maximize the profit of the manufacturer in both models 2 and 3. What is more, the manufacturer using RRSC can obtain more profits generally.

Conclusion 3. By adjusting the ratio $\delta$, the manufacturer can get profits as much as possible, regardless of TTC or RRSC. However, RRSC will lead to a higher profit compared with TTC generally, which is not very difficult to see.

Last but not least, we want to know if RRSC has much better coordination performance than TTC by calculating the total profit of the whole CLSC system.

Conclusion 4. According to results shown in Table 4, we know that both two kinds of coordination contracts can improve all of the players' profits to a great extent, but RRSC seems to perform more efficiently than TTC in the term of coordination. First, the manufacturer (decision maker) can improve the total profit and retailer's effort level by adjusting the ratio of transfer collection price of RRSC easily, as the manufacturer cannot get more total profit and effort level by increasing the fixed transfer payment of TTC. Second, it is clear that the manufacturer can share more profits from the system through RRSC (in model 2, the manufacturer's profits take $57 \%$ of the total profits approximately; however, in model 3, the number is about 70\%). This result is absolutely a great fascination for manufacturers and will lead to their 
TABLE 1: Different optimal choices of $\delta$ under different conditions in model 2.

\begin{tabular}{|c|c|c|c|}
\hline Scenarios & $C_{r 1}^{2} r_{0}-\left(\Delta-P_{r}\right) D C_{r 1} r_{1}^{2}$ & ${ }^{1} A$ & $\delta^{*}$ \\
\hline \multirow{3}{*}{ (1) $2 C_{r 1}^{2} r_{0}-\left(\Delta-P_{r}\right) D C_{r 1} r_{1}^{2} \geq 0$} & 1-1 positive & 1-1-1 positive & 0 \\
\hline & \multirow{2}{*}{ 1-2 negative } & 1-2-1 positive & 1 \\
\hline & & 1-2-2 negative & 2 “ $\sqrt{ } "$ \\
\hline \multirow{2}{*}{ (2) $2 C_{r 1}^{2} r_{0}-\left(\Delta-P_{r}\right) D C_{r 1} r_{1}^{2}<0$} & \multirow{2}{*}{ 2-1 negative } & 2-1-1 positive & $2 “ \sqrt{ } "$ \\
\hline & & 2-1-2 negative & 1 \\
\hline
\end{tabular}

${ }^{1} A=C_{r 1}^{2} r_{0}-\left(\Delta-P_{r}\right) D C_{r 1} r_{1}^{2}+D^{2} P_{r} r_{1}^{4}\left(\Delta-P_{r}\right)+C_{r 1} D P_{r} r_{1}^{2} r_{0}$.

2“ $\sqrt{ }$ " means there is an optimal value of $\delta$ for the manufacturer: $\delta^{*}=\left(\left(\Delta-P_{r}\right) D C_{r 1} r_{1}^{2}-C_{r 1}^{2} r_{0}\right) /\left(D^{2} P_{r} r_{1}^{4}\left(\Delta-P_{r}\right)+C_{r 1} D P_{r} r_{1}^{2} r_{0}\right)$.

TABLE 2: Different optimal choices of $\delta$ under different conditions in model 3.

\begin{tabular}{|c|c|c|c|}
\hline Scenarios & $\lambda^{2} C_{r 1}^{2} r_{0}-\left(\Delta-P_{r}\right) \lambda D C_{r 1} r_{1}^{2}$ & ${ }^{3} B$ & $\delta^{*}$ \\
\hline \multirow{3}{*}{ (1) $\lambda(1+\lambda) C_{r 1}^{2} r_{0}-\left(\Delta-P_{r}\right) \lambda D C_{r 1} r_{1}^{2} \geq 0$} & 1-1 positive & 1-1-1 positive & 0 \\
\hline & \multirow{2}{*}{ 1-2 negative } & 1-2-1 positive & 1 \\
\hline & & 1-2-2 negative & 4 “ $\sqrt{ } "$ \\
\hline \multirow{2}{*}{ (2) $\lambda(1+\lambda) C_{r 1}^{2} r_{0}-\left(\Delta-P_{r}\right) \lambda D C_{r 1} r_{1}^{2}<0$} & \multirow{2}{*}{ 2-1 negative } & 2-1-1 Positive & 4 “ $\sqrt{ } "$ \\
\hline & & 2-1-2 negative & 1 \\
\hline
\end{tabular}

${ }^{3} B=\lambda^{2} C_{r 1}^{2} r_{0}-\left(\Delta-P_{r}\right) \lambda D C_{r 1} r_{1}^{2}+\left(\Delta-P_{r}\right) D^{2} P_{r} r_{1}^{4}+(2-\lambda) C_{r 1} D P_{r} r_{0} r_{1}^{2} \geq 0$.

4 " $\sqrt{ }$ " means there is an optimal value of $\delta$ for the manufacturer: $\delta^{*}=\left(\lambda\left(\Delta-P_{r}\right) D C_{r 1} r_{1}^{2}-\lambda^{2} C_{r 1}^{2} r_{0}\right) /\left((2-\lambda) D C_{r 1} P_{r} r_{0} r_{1}^{2}+\left(\Delta-P_{r}\right) D^{2} P_{r} r_{1}^{4}\right)$.

TABLE 3: Variable assignment ${ }^{5}$.

\begin{tabular}{lccc}
\hline Variable & Assignment & Variable & Assignment \\
\hline$D$ & 573.91 & $r_{0}$ & 0.25 \\
$P$ & 160 & $r_{1}$ & 0.05 \\
$P_{r}$ & 29.57 & $T$ (model 2) & 500 \\
$w$ & 120 & $1-\lambda$ (model 3) & 0.1 \\
$C_{m 1}$ & 110 & $C_{r 0}$ & 1000 \\
$C_{m 2}$ & 6.22 & $C_{r 1}$ & 50 \\
$\Delta$ & 103.78 & $P_{t}$ (model 1) & 35.48 \\
\hline
\end{tabular}

${ }^{5} P_{t}, T$, and $1-\lambda$ are important parameters which will only be used in models 1,2 and 3. Other parameters are common in the three models.

preferences for the RRSC instead of TTC. Finally, we find that, under the given parameters, the retailer's collection effort levels are roughly the same in two models; therefore, there is no big difference between the two types of contracts in terms of introducing incentives to retailers. However, the total profit of model 3 is much higher than that of model 2, which means RRSC can get more profits for the system.

Based on results of this numerical analysis, we confirmed the correctness of our models. Under the specific condition, RRSC indeed has better coordination effect than TTC in those three aspects, which have been shown in the last paragraph.

However, this characteristic condition we assigned in the numerical analysis is just one of the possible conditions we discussed in Section 4. Combining other possible conditions, we could make more suggestions for the retailer and manufacturer from the view of management.
5.1. Insights from the Retailer. As a follower in the game, the retailer is limited within the decision making. He can only decide whether to accept the contract designed by the manufacturer and what the degree of collection effort should be. We discuss the latter question based on the previously calculated results.

5.1.1. What Should the Degree of the Collection Effort Be? During the process of searching for the best response for the retailer and manufacturer, we found the reaction function of the retailer in the two models.

As shown in Table 5, the best response of the collection effort level decided by the retailer is influenced by many elements, including the collection price per unit, the demand for product, and the potential return ratio. The reverse revenue ratio is only defined and assigned in RRSC. If the manufacturer chooses RRSC as coordination contract, then the retailer should select his best response of collection effort level according to the reverse revenue ratio provided by the manufacturer in the contract. The higher the ratio is, the more the collection effort should be devoted.

Additionally, before deciding on the effort level, the retailer has to give a predicted ratio of transfer collection price per unit because the $\delta$ shown in Table 5 is the assumed given ratio of the transfer collection price.

There is not much difference for retailer when deciding the effort level. The only difference is that the retailer has to consider the reverse revenue sharing ratio during the decision procedure under RRSC.

5.1.2. Should the Retailer Accept the Contract? The retailer has the right of refusing. The decision to accept the contract is 


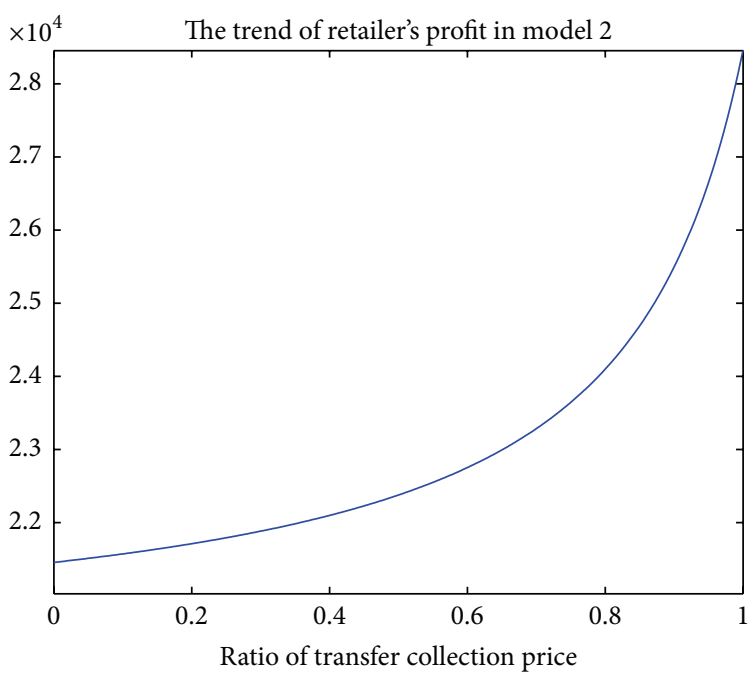

(a) The trend of retailer's profit in model 2

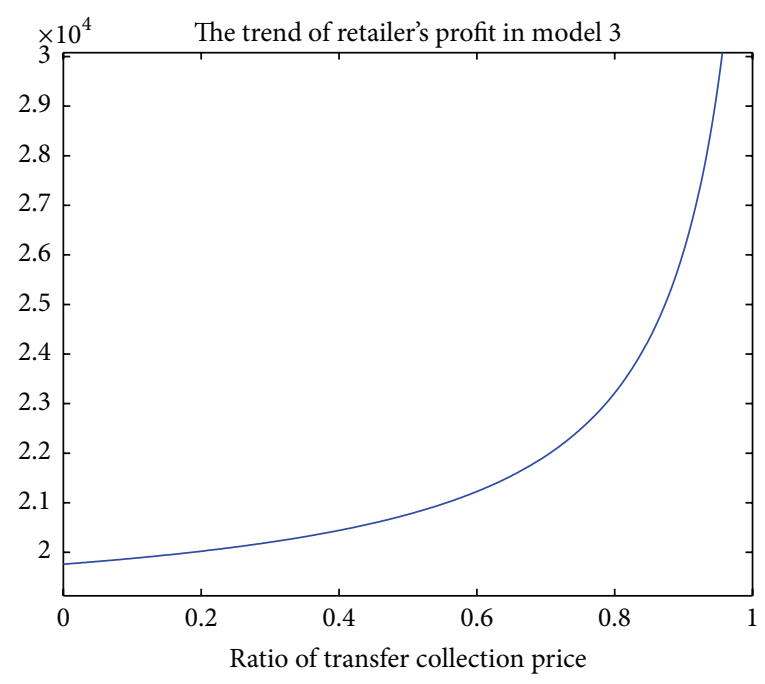

(b) The trend of retailer's profit in model 3

Figure 7: Comparison of the retailer's profit at $e^{*}$ between the two models.

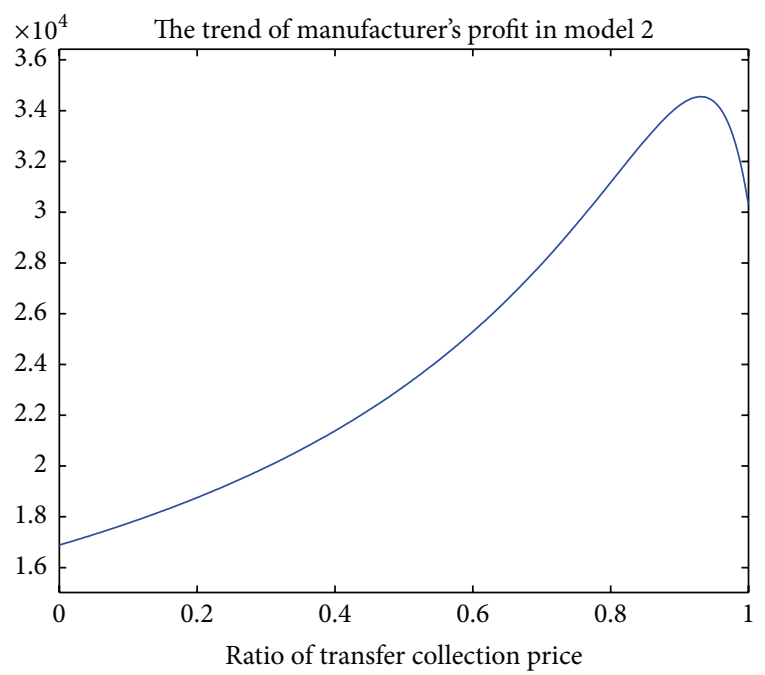

(a) The trend of M's profit in model 2

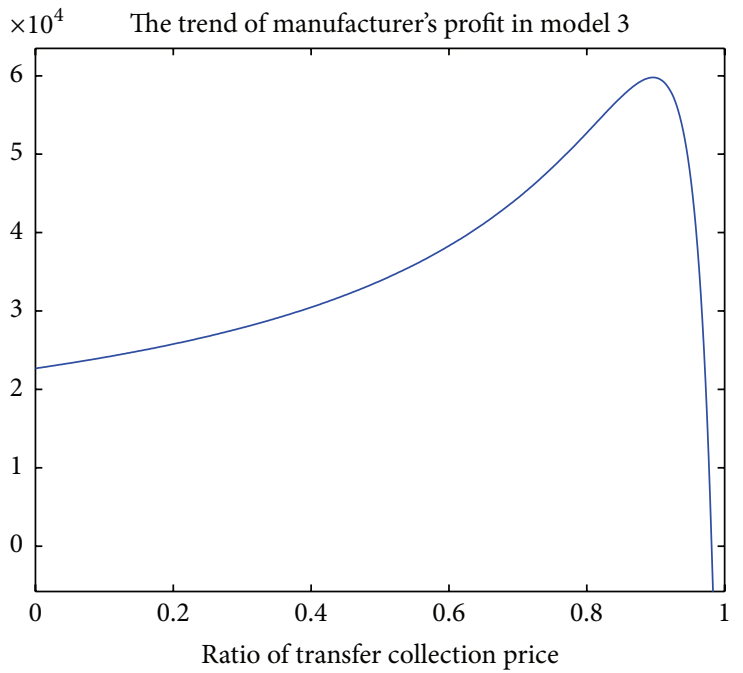

(b) The trend of M's profit in model 3

FIGURE 8: The profit of the manufacturer in two models.

dependent on the profit that the retailer will obtain in the CLSC and the opportunity profit. There is an opportunity that the manufacturer will increase his own profit by increasing the fixed payment paid by the retailer. This increase is an effective strategy for the manufacturer, but it only works within limitations due to the opportunity of the retailer.

The function in (5) is the retailer's profit in model 2.

An increase of fixed payment $T$ will reduce the profit of the retailer. Once the profit decreases under the opportunity profit, the retailer will reject the contract.

This is a defect of TTC because the retailer can estimate the expected profit relatively more easily according to the above function compared with RRSC. The reason is that the value of the transfer payment of TTC is fixed and set clearly in the contract; however, the transfer payment of RRSC is variable and affected not only by the ratio of reverse revenue sharing but also by the reverse revenue.

5.2. Insights from the Manufacturer. As the leader of the game, the manufacturer has more decision-making power than the retailer because he can select the ratio of the transfer collection price after observing the effort level of the retailer, which means the manufacturer has more information than the retailer. Similarly, the manufacturer also has to design the ratio to maximize his profit. According to our findings, the manufacturer is supposed to assign the ratio $\delta$ based on various conditions.

According to the contents in Tables 1 and 2, only under the conditions marked by " $\sqrt{ }$ " the manufacturer can obtain the most profit by adjusting the ratio $\delta$ within the interval of 
TABLE 4: Simulation results comparison between 3 models.

\begin{tabular}{|c|c|c|c|c|c|}
\hline \multicolumn{6}{|c|}{ Model 1} \\
\hline & $\delta^{*}$ & $e^{*}$ & $\begin{array}{c}\text { Manufacturer's } \\
\text { profit }\end{array}$ & $\begin{array}{l}\text { Retailer's } \\
\text { profit }\end{array}$ & $\begin{array}{l}\text { Total } \\
\text { profit }\end{array}$ \\
\hline & Null & 0 & 15538 & 22805 & 38343 \\
\hline \multicolumn{6}{|c|}{ Model 2} \\
\hline$T$ & $\delta^{*}$ & $e^{*}$ & $\begin{array}{l}\text { Manufacturer's } \\
\text { profit }\end{array}$ & $\begin{array}{l}\text { Retailer's } \\
\text { profit }\end{array}$ & $\begin{array}{l}\text { Total } \\
\text { profit }\end{array}$ \\
\hline 625 & 0.9309 & 18.7949 & 34674 & 26030 & 60704 \\
\hline 600 & 0.9309 & 18.7949 & 34649 & 26055 & 60704 \\
\hline 575 & 0.9309 & 18.7949 & 34624 & 26080 & 60704 \\
\hline 550 & 0.9309 & 18.7949 & 34599 & 26106 & 60704 \\
\hline 525 & 0.9309 & 18.7949 & 34574 & 26130 & 60704 \\
\hline 500 & 0.9309 & 18.7949 & 34549 & 26155 & 60704 \\
\hline 475 & 0.9309 & 18.7949 & 34524 & 26180 & 60704 \\
\hline 450 & 0.9309 & 18.7949 & 34499 & 26205 & 60704 \\
\hline 425 & 0.9309 & 18.7949 & 34474 & 26230 & 60704 \\
\hline 400 & 0.9309 & 18.7949 & 34449 & 26255 & 60704 \\
\hline 375 & 0.9309 & 18.7949 & 34424 & 26280 & 60704 \\
\hline \multicolumn{6}{|c|}{ Model 3} \\
\hline$\lambda$ & $\delta^{*}$ & $e^{*}$ & $\begin{array}{c}\text { Manufacturer's } \\
\text { profit }\end{array}$ & $\begin{array}{c}\text { Retailer's } \\
\text { profit }\end{array}$ & $\begin{array}{l}\text { Total } \\
\text { profit }\end{array}$ \\
\hline 0.95 & 0.8856 & 18.9199 & 54993 & 25352 & 80345 \\
\hline 0.94 & 0.8765 & 18.9449 & 55280 & 25091 & 80371 \\
\hline 0.93 & 0.8674 & 18.9699 & 55568 & 24830 & 80398 \\
\hline 0.92 & 0.8583 & 18.9949 & 55855 & 24569 & 80424 \\
\hline 0.91 & 0.8492 & 19.0199 & 56143 & 24307 & 80450 \\
\hline 0.90 & 0.8401 & 19.0449 & 56430 & 24046 & 80476 \\
\hline 0.89 & 0.8310 & 19.0699 & 56718 & 23784 & 80502 \\
\hline 0.88 & 0.8219 & 19.0949 & 57006 & 23523 & 80529 \\
\hline 0.87 & 0.8128 & 19.1199 & 57294 & 23261 & 80555 \\
\hline 0.86 & 0.8036 & 19.1449 & 57528 & 22999 & 80527 \\
\hline 0.85 & 0.7945 & 19.1699 & 57870 & 22737 & 80607 \\
\hline
\end{tabular}

TABLE 5: Reaction function of the retailer.

\begin{tabular}{ll}
\hline Model 2 & Model 3 \\
\hline$e^{*}(\delta)=\frac{\delta P_{r} D r_{1} r_{0}}{C_{r 1}-\delta P_{r} D r_{1}^{2}}$ & $e^{*}(\delta)=\frac{\delta P_{r} D r_{1} r_{0}}{\lambda C_{r 1}-\delta P_{r} D r_{1}^{2}}$ \\
\hline
\end{tabular}

$\delta \in[0,1]$, and the optimal choice of $\delta$ is not very difficult to estimate:

$$
\begin{aligned}
\delta^{*} & =\frac{\left(\Delta-P_{r}\right) D C_{r 1} r_{1}^{2}-C_{r 1}^{2} r_{0}}{D^{2} P_{r} r_{1}^{4}\left(\Delta-P_{r}\right)+C_{r 1} D P_{r} r_{1}^{2} r_{0}} \\
\text { or } \delta^{*} & =\frac{\lambda\left(\Delta-P_{r}\right) D C_{r 1} r_{1}^{2}-\lambda^{2} C_{r 1}^{2} r_{0}}{(2-\lambda) D C_{r 1} P_{r} r_{0} r_{1}^{2}+\left(\Delta-P_{r}\right) D^{2} P_{r} r_{1}^{4}} .
\end{aligned}
$$

In fact, we have to take other elements, such as the return rate, into consideration when deciding the types of coordination contract.

The European Union (EU) has set a minimum limit for the return rate of plastic products: $28 \%$. In the United States, companies with high return rates in some industries have more preferential policies than others. In addition, during the period prior to CLSC's construction, a large amount of fixed cost was caused by advertising and purchasing remanufactured devices, so the manufacturer must raise the return rate to amortize the cost.

The evidence suggests that the return rate is an important element when deciding the type of coordination contract in CLSC. Therefore, the manufacturer balances the two elements, profit and return rate, during the decision making process. Under the given condition shown in the numerical analysis, RRSC is more successful than TTC in the term of enhancing the return rate.

\section{Conclusion}

In this paper, we have built a Stackelberg Game model within a CLSC system in which the manufacturer takes the role of leader and the retailer acts as the follower. To integrate the retailer into this CLSC system so that the manufacturer can obtain more benefit from the collection activities, the manufacturer has to provide satisfactory contracts to the retailer. According to the past literature, we chose two types of contracts, reverse revenue sharing contracts and two-part tariff contracts, as the negotiation mechanism.

In models of this paper, the manufacturer, as the leader of the whole supply chain, assumes the maximization of his own profit as the target of the coordination. At the same time, he has to take the profit of the retailer into consideration; therefore, we postulate the maximization of the profit of the retailer as the constraint condition.

By considering several different scenarios, we found that the profit of the manufacturer has different trends as the growth of the ratio $\delta$ under disparate conditions shown in the Tables 1 and 2. Under some conditions, the optimal decision of $\delta$ is simply 0 or 1 , but under other conditions, denoted by " $\sqrt{ }$ " the optimal decision of $\delta$ can be calculated by the equations: $\delta^{*}=\left(\left(\Delta-P_{r}\right) D C_{r 1} r_{1}^{2}-C_{r 1}^{2} r_{0}\right) /\left(D^{2} P_{r} r_{1}^{4}\left(\Delta-P_{r}\right)+\right.$ $\left.C_{r 1} D P_{r} r_{1}^{2} r_{0}\right)$, if the manufacturer chooses the TTC as their coordination contract, and otherwise $\delta^{*}=\left(\lambda\left(\Delta-P_{r}\right) D C_{r 1} r_{1}^{2}-\right.$ $\left.\lambda^{2} C_{r 1}^{2} r_{0}\right) /\left((2-\lambda) D C_{r 1} P_{r} r_{0} r_{1}^{2}+\left(\Delta-P_{r}\right) D^{2} P_{r} r_{1}^{4}\right)$.

On one hand, our research can be used as the guidelines for the tactical decisions about the type of coordination contract in a CLSC: compared with two-part tariff contract, reverse revenue sharing contract has more advantages. Also, the manufacturer can improve the total profits and retailer's collection efforts by adjusting the ratio of transfer collection price conveniently. This is meaningful because the manufacturer may have long-period cooperation with retailer, and they can make adjustments according to actual conditions through RRSC. On the other hand, by using RRSC, manufacturers will share more profits from the total profits, which is a great attraction for them. Therefore, taking all of the results into consideration, RRSC has better coordination performance than the TTC, based on models described in this paper. Besides, we also give the function of calculating $\delta$ to maximize manufacturers' profit, which may be valuable guidelines for manufacturers. However, our 
established models are built on a relatively simple CLSC structure, including one manufacturer and one retailer. The future research can consider one common manufacturer and numerous competitive retailers or vice versa. Additionally, all of the reverse activities in this paper occur in one period; however, the multiple periods are also considerable.

\section{Competing Interests}

The authors declare that they have no competing interests.

\section{Acknowledgments}

The research presented in this paper is supported by the National Natural Science Foundation Project of China (71390331, 71572138, 71271168, and 71371150), the National Social Science Foundation Project of China (12\&ZD070), the National Soft Science Project of China (2014GXS4D151), the Soft Science Project of Shaanxi province (2014KRZ04), the Program for New Century Excellent Talents in University (NCET-13-0460), and the Fundamental Research Funds for the Central Universities.

\section{References}

[1] D. S. Khetriwal, P. Kraeuchi, and R. Widmer, "Producer responsibility for e-waste management: key issues for considerationlearning from the Swiss experience," Journal of Environmental Management, vol. 90, no. 1, pp. 153-165, 2009.

[2] C. R. D. de Oliveira, A. M. Bernardes, and A. E. Gerbase, "Collection and recycling of electronic scrap: a worldwide overview and comparison with the Brazilian situation," Waste Management, vol. 32, no. 8, pp. 1592-1610, 2012.

[3] V. D. R. Guide Jr. and L. N. Van Wassenhove, "The evolution of closed-loop supply chain research," Operations Research, vol. 57, no. 1, pp. 10-18, 2009.

[4] H. Krikke, I. Le Blanc, and S. van de Velde, "Product modularity and the design of closed-loop supply chains," California Management Review, vol. 46, no. 2, pp. 23-39, 2004.

[5] M. Zu-Jun, N. Zhang, Y. Dai, and S. Hu, "Managing channel profits of different cooperative models in closed-loop supply chains," Omega, vol. 59, pp. 251-262, 2016.

[6] R. Aydin, C. K. Kwong, and P. Ji, "Coordination of the closedloop supply chain for product line design with consideration of remanufactured products," Journal of Cleaner Production, vol. 114, pp. 286-298, 2016.

[7] J.-M. Chen and C.-I. Chang, "The co-opetitive strategy of a closed-loop supply chain with remanufacturing," Transportation Research Part E: Logistics and Transportation Review, vol. 48, no. 2, pp. 387-400, 2012.

[8] P. De Giovanni, P. V. Reddy, and G. Zaccour, "Incentive strategies for an optimal recovery program in a closed-loop supply chain," European Journal of Operational Research, vol. 249, no. 2, pp. 605-617, 2016.

[9] V. D. R. Guide Jr. and L. N. Van Wassenhove, "Closed-loop supply chains: an introduction to the feature issue (part 2)," Production and Operations Management Society, vol. 15, no. 3, pp. 345-350, 2006.

[10] N.-N. Yan and B.-W. Sun, "Optimal stackelberg strategies for closed-loop supply chain with third-party reverse logistics,"
Asia-Pacific Journal of Operational Research, vol. 29, no. 5, Article ID 1250026, 21 pages, 2012.

[11] G. Jing-Yan, H. Pei-Qing, and W. Zi-Ping, "Coordination and information sharing in a closed-loop supply chain with twopart tariff,' in Proceedings of the IEEE International Conference on Service Operations and Logistics, and Informatics (SOLI '06), pp. 304-309, Shanghai, China, June 2006.

[12] K. Govindan, M. N. Popiuc, and A. Diabat, "Overview of coordination contracts within forward and reverse supply chains," Journal of Cleaner Production, vol. 47, pp. 319-334, 2013.

[13] Y. Wang, L. Jiang, and Z.-J. Shen, “Channel performance under consignment contract with revenue sharing," Management Science, vol. 50, no. 1, pp. 34-47, 2004.

[14] K. Govindan and M. N. Popiuc, "Reverse supply chain coordination by revenue sharing contract: a case for the personal computers industry," European Journal of Operational Research, vol. 233, no. 2, pp. 326-336, 2014.

[15] F. Schultmann, M. Zumkeller, and O. Rentz, "Modeling reverse logistic tasks within closed-loop supply chains: an example from the automotive industry," European Journal of Operational Research, vol. 171, no. 3, pp. 1033-1050, 2006.

[16] M. Jeihoonian, M. Kazemi Zanjani, and M. Gendreau, "Accelerating Benders decomposition for closed-loop supply chain network design: case of used durable products with different quality levels," European Journal of Operational Research, vol. 251, no. 3, pp. 830-845, 2016.

[17] J. Wei, K. Govindan, Y. Li, and J. Zhao, "Pricing and collecting decisions in a closed-loop supply chain with symmetric and asymmetric information," Computers and Operations Research, vol. 54, pp. 257-265, 2015.

[18] S. H. Yoo, D. S. Kim, and M.-S. Park, "Pricing and return policy under various supply contracts in a closed-loop supply chain," International Journal of Production Research, vol. 53, no. 1, pp. 106-126, 2015.

[19] S. K. Jena and S. P. Sarmah, "Price competition and co-operation in a duopoly closed-loop supply chain," International Journal of Production Economics, vol. 156, pp. 346-360, 2014.

[20] Arshinder, A. Kanda, and S. G. Deshmukh, "Supply chain coordination: perspectives, empirical studies and research directions," International Journal of Production Economics, vol. 115, no. 2, pp. 316-335, 2008.

[21] C. T. Linh and Y. Hong, "Channel coordination through a revenue sharing contract in a two-period newsboy problem," European Journal of Operational Research, vol. 198, no. 3, pp. 822-829, 2009.

[22] Y. Gerchak and Y. Wang, "Revenue-sharing vs. wholesaleprice contracts in assembly systems with random demand," Production and Operations Management, vol. 13, no. 1, pp. 23-33, 2004.

[23] S. Luo and M. Çakanyilirim, "Pricing and production games under revenue sharing and information updates," Journal of Revenue \& Pricing Management, vol. 4, no. 3, pp. 270-301, 2005.

[24] P. De Giovanni and G. Zaccour, "A two-period game of a closedloop supply chain," European Journal of Operational Research, vol. 232, no. 1, pp. 22-40, 2014.

[25] K. Govindan, H. Soleimani, and D. Kannan, "Reverse logistics and closed-loop supply chain: a comprehensive review to explore the future," European Journal of Operational Research, vol. 240, no. 3, pp. 603-626, 2015. 
[26] R. C. Canan Savaskan, S. Bhattacharya, and L. N. Van Wassenhove, "Closed-loop supply chain models with product remanufacturing," Management Science, vol. 50, no. 2, pp. 239-252, 2004.

[27] N. Yan and S. Baowen, "Designing coordination contract for closed-loop supply chain based on material recycling," International Journal of Business Research, vol. 11, no. 4, pp. 174-179, 2011.

[28] T.-M. Choi, Y. Li, and L. Xu, "Channel leadership, performance and coordination in closed loop supply chains," International Journal of Production Economics, vol. 146, no. 1, pp. 371-380, 2013.

[29] G. P. Cachon, "Supply chain coordination with contracts," in The Handbook of Operations Research and Management Science: Supply Chain Management, S. C. Graves and T. de Kok, Eds., Kluwer Academic, Amsterdam, Netherlands, 2003.

[30] M. Nagarajan and G. Sošić, "Game-theoretic analysis of cooperation among supply chain agents: review and extensions," European Journal of Operational Research, vol. 187, no. 3, pp. 719-745, 2008.

[31] M. Leng and M. Parlar, "Game-theoretic analyses of decentralized assembly supply chains: non-cooperative equilibria vs. coordination with cost-sharing contracts," European Journal of Operational Research, vol. 204, no. 1, pp. 96-104, 2010.

[32] Y. Qi, W. Ni, and K. Shi, "Game theoretic analysis of one manufacturer two retailer supply chain with customer market search," International Journal of Production Economics, vol. 164, pp. 57-64, 2015.

[33] C.-S. Shi and C.-T. Su, "Integrated inventory model of returnsquantity discounts contract," Journal of the Operational Research Society, vol. 55, no. 3, pp. 240-246, 2004. 


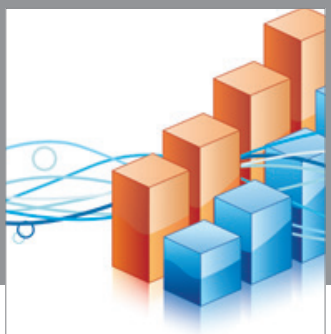

Advances in

Operations Research

vatem alat4

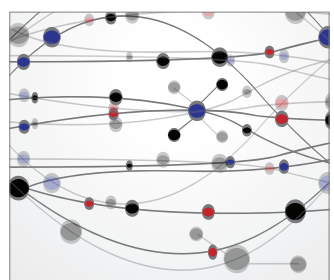

\section{The Scientific} World Journal
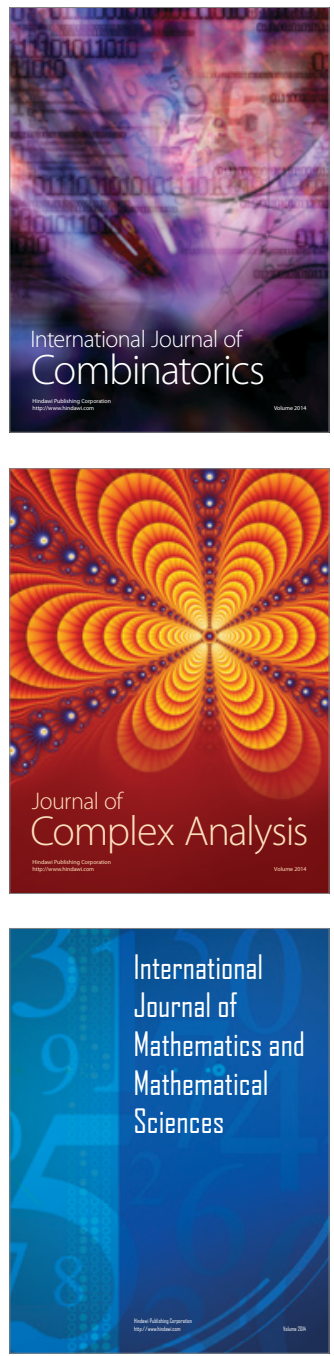
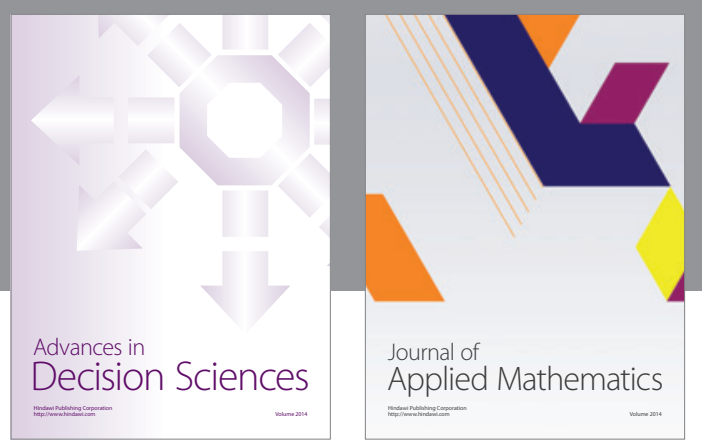

Algebra

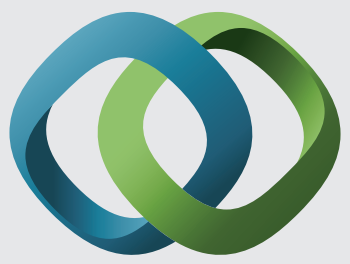

\section{Hindawi}

Submit your manuscripts at

http://www.hindawi.com
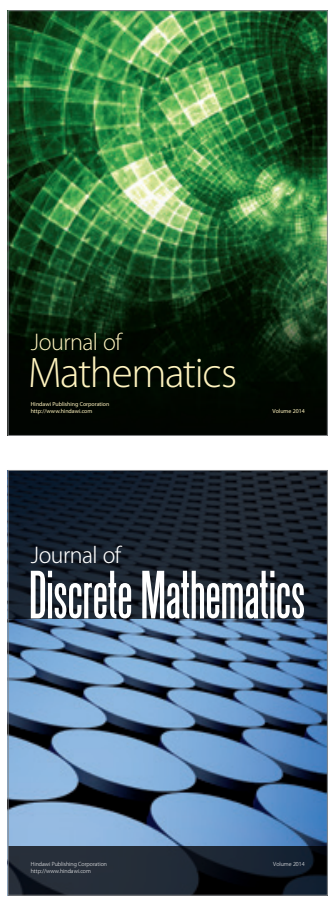

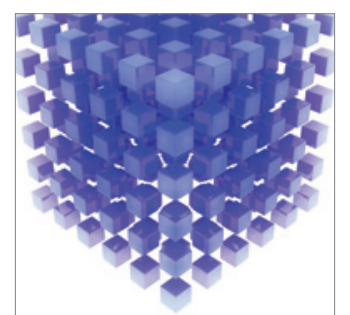

Mathematical Problems in Engineering
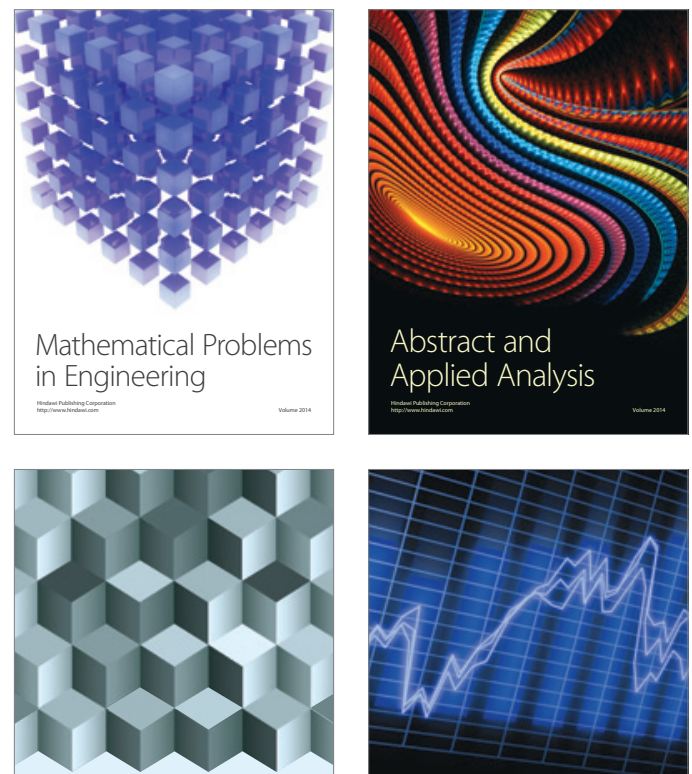

Journal of

Function Spaces

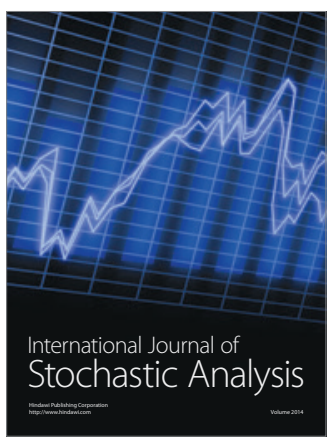

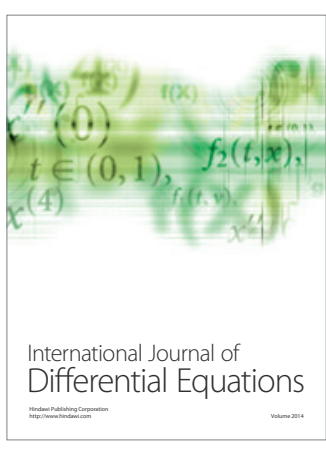
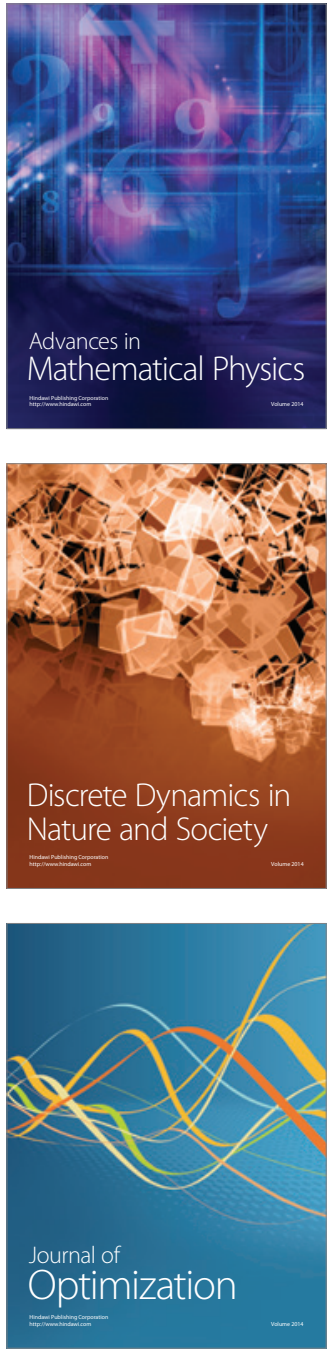